\title{
Synergistic Effects of Adding a Substrate and an Organic Reductant for Stimulating the Bioremediation of 4-chloronitrobenzene- contaminated Soil
}

Tian Li ( $D$ lihwang@swu.edu.cn )

Southwest University, Chongqing 400715, P. R. China; https://orcid.org/0000-0003-1618-7175

Ping Zhang

Southwest University

Kun Qian

Southwest University

Tian.C Zhang

University of Nebraska-lincoln

Research

Keywords: 4-chloronitrobenzene, co-metabolicpathways, synergistic effect, soil, approach

Posted Date: August 20th, 2020

DOI: https://doi.org/10.21203/rs.3.rs-57928/v1

License: (c) (1) This work is licensed under a Creative Commons Attribution 4.0 International License.

Read Full License 


\section{Abstract}

Background:Soil contaminated with 4-chloronitrobenzene (4NCB) is resistant to microbial degradation due to the electron-withdrawing properties of the nitro and chloro groups in 4NCB. Currently, sufficient information is not available on how to use biostimulation strategies to enhance the bioremediation of 4NCB-contaminated soil.

Results:In the present study, a novel strategy was developed by utilizing the synergistic effects of adding an organic reductant (ascorbic acid, VC) and an organic nitrogen source (peptone) to stimulate the biodegradation of 4 NCB-contaminated soil. Using this strategy, the bioremediation of $1 \mathrm{~g}-4 \mathrm{NCB} / \mathrm{kg}-1$ soil could be completed within 8 days in soil batch reactors. Furthermore, the study discovered two 4NCB cometabolic intermediates in the soil reactors added with peptone and VC, and for the first time, 4NCB was transformed to 4-chlorofromanilide.

Conclusion:The proposed strategy is promising because it is highly efficient, easy to control and involves a non-toxic, environmentally friendly substrate/reductant.). Finally, this approach warrants future studies to extend its applications to soils contaminated with other nitroaromatic compounds.

\section{Background}

A typical chlorinated nitroaromatic intermediate compound, 4-chloronitrobenzene (4NCB), has been released into the environment for many years due to its extensive use in the chemical synthesis of drugs, herbicides, dyes, and other industrial chemicals [1]. In addition, the worldwide area of soil contaminated with 4 NCB has substantially increased because of inappropriate use and accidental leakage. Soil contamination by $4 \mathrm{NCB}$ is resistant to microbial degradation due to the electron-withdrawing properties of its nitro and chloro groups [2]. However, the important role that the microbial community plays in the degradation of organic xenobiotics in the environment is now clearly recognized [3]. Therefore, exploring highly efficient bioremediation methods for accelerating the biodegradation rates of contaminated soils, which typically contain a complex microbial community structure, is important for soil remediation.

The aim of bioremediation is to accelerate the biodegradation rate via two approaches (bioaugmentation and biostimulation) [4]. Bioaugmentation is a promising approach for cleaning soil contamination [5]; however, the challenge with this approach is to introduce a specific strain or a consortium of microorganisms with low levels of survival in complex soil ecosystems [6]. There have been a number of studies to isolated and characterized microorganisms with the capacity to degrade 4NCB [7-11]. However, only two studies have successfully performed bioaugmentation using the inoculated strain at the laboratory scale $[10,11]$.

There are two opposing viewpoints in the comparison of biostimulation and bioaugmentation as strategies for remediation of soil contaminated by organic compounds and determining which strategy is more appropriate to enhance the organic biodegradation rate $[12,13]$. However, to the best of our escribing biostimulation strategies to address 4NCB- 
contaminated soil. Biostimulation, which is an important bioremediation technology, has received extensive recognition because of its following advantages [14]. 1) The technology is simple, inexpensive and "green" and can be easily controlled by adding the active compounds; moreover, biostimulation does not require much time to isolate a specific strain or a consortium of microorganisms with the capability to biodegrade 4NCB [15]. 2) Biostimulation has been used to stimulate the activity and biomass of indigenous microorganisms to enhance the degradation rate. Thus, the survival of indigenous microorganisms used for biostimulation in the target soils is not problematic [16, 17]. However, the use of biostimulation faces a key problem of how to effectively enhance the ability of soil microorganisms to biodegrade.

In the present work, a simple and "green" method was utilized for effectively enhancing 4NCB removal in soil. A novel approach was previously established to utilize the synergistic effect of an organic reductant and a co-substrate that could effectively enhance the nitroaromatic compounds (4NCB and nitrobenzene) biodegradation rate of the strain as a pure culture $[18,19]$. In the experimental stages, a system was established using a mineral salt medium (MSM) with soil microorganisms, as soil compounds could interfere with 4 NCB removal by soil microbial biodegradation if an additional compound was used. To compare the two systems (soil and MSM), the results of the experiments identified the soil compounds that affected the 4 NCB removal rate. Moreover, an additional reductant could affect the concentration of co-metabolite and the 4NCB biodegradation co-metabolic pathway; therefore, identifying the 4NCB biodegradation pathway involved in the approach is important. Certain studies have identified the pathway under aerobic conditions, but none have identified the 4 NCB removal co-metabolic pathway. The objectives of the present study were 1) to evaluate whether this approach effectively enhanced the 4NCB biodegradation rate of the microbial communities in soil, 2) to evaluate whether 4NCB contamination in soil could be effectively removed using the approach, and 3) to evaluate the co-metabolic pathway of 4 NCB removal from soil using the approach.

\section{Materials And Methods}

\section{Soil}

The selected soil was classified as a light clay loam soil collected from the vegetable garden of Chongqing, and did not contain $4 \mathrm{NCB}$, even in trace amounts. The sample was taken from the top layer $(0-15 \mathrm{~cm})$ and stored in the dark at $4{ }^{\circ} \mathrm{C}$ until use. Its main properties were as follows: real alkalinity [in water], pH 7.8; water content, $18 \%$; total organic carbon, $1.3 \%$; total nitrogen $0.089 \%$; soil texture: sand, $38.6 \%$; silt, $25.2 \%$; and clay, $40 \%$.

\section{Experimental Process}

The experiment was designed to be divided into two experimental stages. The first stage was intended to analvze the effect of exnoenous comnounds (substrate, reducing agent or substrate + reducing agent) on Loading [MathJax]/jax/output/CommonHTML/jax.js 
4NCB biodegradation by indigenous microorganisms from soil. Batch experiments for the first stage were conducted using $250 \mathrm{~mL}$ bottles filled with $50 \mathrm{~mL}$ of reaction solution and placed in a rotary shaker at $28^{\circ} \mathrm{C}$ and $180 \mathrm{rpm}$ for 3 days (Table 1). This part of the testing was conducted in four sets, as shown in Table 1. All of the $50 \mathrm{~mL}$ reaction solutions (MSM) contained $0.1 \mathrm{~g}$ of soil and $100 \mathrm{mg} / \mathrm{L} 4 \mathrm{NCB}$. Some of the solutions also contained additional reagents (Table 1 ). 
Table 1

Experimental sets and conditions
Test
Substrate Reductant
set
4- Experimental purpose
NCB

The first stage (MSM): each batch reactor contained: 1) $0.1 \mathrm{~g}$ soil; 2) $4 \mathrm{NCB}$ of $100 \mathrm{mg} \mathrm{L}^{-1}$; and 3) $49 \mathrm{~mL}$ mineral salt medium (MSM) with or without adding substrate and/or reductant:

\begin{tabular}{|c|c|c|c|c|}
\hline $\begin{array}{l}\text { Set } \\
1\end{array}$ & - & - & + & $\begin{array}{l}\text { Testing the capacity of the indigenous microorganisms } \\
\text { for biodegradation of } 4 \mathrm{NCB} \text {; results were used as a } \\
\text { benchmark (the control tests) }\end{array}$ \\
\hline $\begin{array}{l}\text { Set } \\
2\end{array}$ & + & - & + & $\begin{array}{l}\text { Testing the biostimulation of the indigenous } \\
\text { microorganisms for } 4 \text { NCB biodegradation by adding an } \\
\text { additional substrate (e.g., } 1 \% \text { of sucrose or starch or } \\
\text { ammonium nitrate or urea or peptone) }\end{array}$ \\
\hline
\end{tabular}

Set - $+\quad+\quad \begin{aligned} & \text { Testing the biostimulation of the indigenous } \\ & 3 \\ & \text { microorganisms for 4NCB biodegradation by adding one } \\ & \text { of the reductant [e.g., } 0.02 \% \text { of Fe } \mathrm{Fe}^{2+} \text { or D-glucose or VC } \\ & \text { (= ascorbic acid ) or mannitol] }\end{aligned}$

$\begin{array}{ll}\text { Set } & +\quad+\quad \begin{array}{l}\text { Testing the biostimulation of the indigenous } \\ \text { microorganisms for 4NCB biodegradation under the } \\ \text { influence of adding one of the } 5 \text { reductants and one } \\ \text { substrate (peptone) }\end{array}\end{array}$

The second stage (soil): each batch reactor contained $50 \mathrm{~g}$ soils mixed with $100 \mathrm{mg}-4 \mathrm{NCB} \mathrm{Kg}^{-1}$ soil (W/W) with a moisture content of $20 \%$ for sets $1-4$, and $1 \mathrm{~g}-4 \mathrm{NCB} \mathrm{Kg}{ }^{-1}$ soil (w/w) for set 5 with or without adding substrate and/or reductant with the concentration the same as the corresponding sets in the first stage:

\begin{tabular}{|c|c|c|c|c|}
\hline $\begin{array}{l}\text { Set } \\
1\end{array}$ & - & - & + & $\begin{array}{l}\text { Testing the capacity of the soil for } 4 \text { NCB biodegradation; } \\
\text { results were used as a benchmark }\end{array}$ \\
\hline $\begin{array}{l}\text { Set } \\
2\end{array}$ & + & - & + & $\begin{array}{l}\text { Testing the biostimulation of the soil for } 4 \mathrm{NCB} \\
\text { biodegradation by adding each of the five substrates }\end{array}$ \\
\hline $\begin{array}{l}\text { Set } \\
3\end{array}$ & - & + & + & $\begin{array}{l}\text { Testing the biostimulation of the soil for } 4 \mathrm{NCB} \\
\text { biodegradation by adding each of the five reductants }\end{array}$ \\
\hline $\begin{array}{l}\text { Set } \\
4\end{array}$ & + & + & + & $\begin{array}{l}\text { Testing the biostimulation of the soil for } 4 \mathrm{NCB} \\
\text { biodegradation by adding one of the } 5 \text { reductants and } \\
\text { one substrate (peptone) }\end{array}$ \\
\hline $\begin{array}{l}\text { Set } \\
5\end{array}$ & + & + & + & $\begin{array}{l}\text { Testing the biostimulation of the soil for biodegradation } \\
\text { of } 4 \mathrm{NCB} \text { with a high concentration }\left[1 \mathrm{~g}-4 \mathrm{NCB} \mathrm{Kg}{ }^{-1} \text { soil }\right. \\
\text { (w/w)] by adding VC and peptone and finding the } \\
\text { associated metabolite of } 4 \mathrm{NCB}\end{array}$ \\
\hline
\end{tabular}

Note: 


\section{$\begin{array}{lllll}\begin{array}{l}\text { Test } \\ \text { set }\end{array} & \text { Substrate } & \text { Reductant } & \text { N- } & \text { Experimental purpose }\end{array}$}

- In the first stage: All of the $50 \mathrm{~mL}$ reaction solutions contained: 1) $0.1 \mathrm{~g}$ soil; 2) $4 \mathrm{NCB}$ (final concentration $=100 \mathrm{mg} \mathrm{L}^{-1}$; and 3) $49 \mathrm{~mL}$ mineral salt medium (MSM). + represents the additional substance (substrate or reductant); - represents without the additional substance. In Set 2, substrate represents $1 \%$ sucrose or $1 \%$ peptone or $1 \%$ starch or $1 \%$ ammonium nitrate or $1 \%$ urea (W/W); in Set 3 , reductant represents $0.02 \% \mathrm{Fe}^{2+}$, or $0.02 \%$ D-glucose, or $0.02 \% \mathrm{VC}$ (= L-lactose) or $0.02 \%$ mannitol $(\mathrm{W} / \mathrm{W})$; In set 4 , substrate represents $1 \%$ peptone $(\mathrm{w} / \mathrm{w})$, and reductant represents $0.02 \%$ of each of the 4 reductants [i.e., $\mathrm{Fe}^{2+}, \mathrm{D}$-glucose, $\mathrm{VC}$, mannitol]. The 4-NCB concentration in the batch reactor was $100 \mathrm{mg} \mathrm{L}^{-1}$ for sets $1-4$.

- In the second stage: All of the $50 \mathrm{~g}$ soils (4NCB and the soil were mixed up to complete homogenization) contained the following: 1 ) the same concentration of additional substance as sets 1-4 of the first stage; 2$)$ set 5 : substrate represents $1 \%$ peptone $(\mathrm{w} / \mathrm{w})$, and reductant represents $0.02 \% \mathrm{VC}(\mathrm{w} / \mathrm{w})$. The $4 \mathrm{NCB}$ concentration in the soil was $100 \mathrm{mg}-4 \mathrm{NCB} \mathrm{Kg}{ }^{-1}$ soil $(\mathrm{W} / \mathrm{W})$ for sets $1-4$, and $1 \mathrm{~g}-4 \mathrm{NCB} \mathrm{Kg}{ }^{-1}$ soil $(\mathrm{w} / \mathrm{w})$ for set 5 ; the moisture of the all reactors in the second stage was $20 \%$.

In the second stage of experiments, we evaluated the effect on 4NCB biodegradation rates in the soil resulting from the addition of exogenous compounds (organic reducing agent, substrate). The biostimulation experiments in soil were conducted in $250 \mathrm{~mL}$ bottles at $28{ }^{\circ} \mathrm{C}$, and $50 \mathrm{~g}$ of contaminated soil was used without sterilization to maintain the water content (4NCB and the soil were mixed to complete homogenization, and $4 \mathrm{NCB} / \mathrm{soil}=100 \mathrm{mg} / 1 \mathrm{~kg}$ or $1 \mathrm{~g} / 1 \mathrm{~kg}, \mathrm{w} / \mathrm{w}$ ). Each of the $50 \mathrm{~g}$ of contaminated soil components contained additional reagents (Table 1 ), and this part of the testing was conducted in five sets, as shown in Table 1. The 4NCB residue contents in soil were extracted as previously described [11].

The densities of the indigenous microorganisms $\left(O D_{600}\right)$ and the $4 \mathrm{NCB}$ concentrations were measured after 72 hours in all sets except Set 5 in the second stage of the experiment (samples were withdrawn periodically for the analysis the $4 \mathrm{NCB}$ contents). In addition, the samples of Set 5 in the second stage of the experiment were utilized after 8 days to identify the intermediates of $4 \mathrm{NCB}$. Each experiment was replicated four times $(n=4)$.

\section{Analytical Procedures}

The concentrations of 4NCB were measured using high-performance liquid chromatography (HPLC) (Agilent 1260, Wilmington, DE, USA) on an instrument equipped with an Agilent Extend-C18 column (150 $\mathrm{mm} \times 4.6 \mathrm{~mm})$. The analyses were performed with a flow of methanol/water $(\mathrm{v} / \mathrm{v}, 7: 3)$ at a rate of $1.0 \mathrm{~mL}$ $\min ^{-1}$. The bacterial cell density was measured as $O D_{600}$.

The identification of the degradation intermediates of 4 NCB was conducted using gas chromatographmass spectrometry (GC/MS 7890B, Agilent, USA). The GC/MS was configured with an Agilent HP-5 MS (30 $\mathrm{m} \times 0.25 \mathrm{~mm}$ i.d. $\times 0.25 \mu \mathrm{m}$ ) column. Helium (purity 99.999\%) was employed as the carrier gas with a Loading [MathJax]/jax/output/CommonHTML/jax.js itial temperature was held at $50{ }^{\circ} \mathrm{C}$ for 5 min, after which the 
temperature was increased to $150^{\circ} \mathrm{C}$ and held for $20 \mathrm{~min}$ and then increased again to $270{ }^{\circ} \mathrm{C}$ and held for 20 min.

\section{Results}

\section{Effect of the Substrate on 4NCB Reduction.}

The microbial community plays an important role in the biodegradation of organic xenobiotics in soil [20]. A novel approach was previously established that could effectively enhance the biodegradation rate of nitroaromatic compounds using pure strains [10, 11]; however, complex microbial populations and complex soil compounds exist in the soil. Here, the intent was to evaluate effect on 4NCB degradation using an additional compound in two systems (MSM, soil).

The effect of the additional substrate on the $4 \mathrm{NCB}$ removal and the $O D$ values of soil microorganisms were observed in the MSM after 3 days. At a concentration of $100 \mathrm{mg} / \mathrm{L} 4 \mathrm{NCB}$, minimal indigenous microorganisms existed that could utilize $4 \mathrm{NCB}$ as carbon and nitrogen sources to grow, as shown in Fig. $1 \mathrm{~A}\left(0.160 \pm 0.022\right.$, the $O D_{600}$ value for the indigenous microorganisms of the control group), and higher levels of 4 NCB would be difficult to remove by indigenous microorganisms (the 4NCB degradation for the control $=16.9 \%$ ). Thus, an increase in the biomass of the indigenous microorganisms could be a key factor affecting 4 NCB biodegradation. Therefore, testing the effect of a normal substrate on the biomass of the indigenous microorganisms to enhance 4 NCB removal was required in the next stage of the experiment. First, with additional carbon (sucrose, starch), The biomass of indigenous microorganisms $\left(O D_{600}\right.$ values $=0.301 \pm 0.083$ and $0.456 \pm 0.122$, respectively $)$ and the degradation of 4 NCB residue (19.2\% and $17.5 \%$, respectively) indicated minimal increases compared with the data for the control (Fig. 1A). The results indicated that the indigenous microorganisms could not sufficiently utilize the additional carbon to enhance the strain's growth and therefore did not produce an increase in the $4 \mathrm{NCB}$ biodegradation rate. Second, with inorganic nitrogen sources (ammonium nitrate or urea) $\left(O D_{600}\right.$ values $=0.274 \pm 0.022$ and $0.3446 \pm 0.0607$, respectively $)$, an increase in the 4 NCB biodegradation rate was not apparent compared with the control data; however, the $4 \mathrm{NCB}$ data $(11.7 \%$ and $14.0 \%$, respectively) indicated that the biodegradation rates had been slightly suppressed. Finally, the effect of adding inorganic nitrogen sources on the 4 NCB biodegradation rates was opposite to that of indigenous strains from soil. Supplementation with organic nitrogen (peptone) markedly improved the $O D_{600}$ value (1.54), and the 4 NCB degradation was $62.9 \%$ after 3 days. The results indicated that the substantial enhancement of indigenous microbial growth was induced organically and resulted in increased 4NCB biodegradation.

For all the biostimulated substrates in soil, the highest level of 4NCB degradation (78.3\%) was found to be a result of supplementation with peptone. No substantial difference was observed in 4NCB degradation (51.9\% and $46.2 \%$, respectively) with a carbon source (sucrose or starch), and the degradation (48.8\% and $43.1 \%$, respectively) was limited with an inorganic source (urea or ammonium 
nitrate). Considering these results, peptone was determined to be the optimal primary substrate for our subsequent experiments.

\section{Effect of the Reductant on 4NCB Reduction.}

4 NCB is resistant to microbial degradation due to the simultaneous existence of chlorine and nitro groups, which may induce a partial reduction of 4 NCB in the initial steps. Thus, a reductant could enhance 4NCB biodegradation by pure strains (11). Therefore, we tested the effect of an additional reductant on the $4 \mathrm{NCB}$ removal and the $O D$ values of the soil microorganisms. Figure $1 \mathrm{~A}$ shows that were no statistically significant differences between the $O D_{600}$ values for the additional reductant and those for the control group. This finding refutes the assumption that a reductant cannot be utilized as a substrate to support microbial growth. When reductants (D-glucose, mannitol, ascorbic acid (VC), and $\mathrm{FeSO}_{4}\left(\mathrm{Fe}^{2+}\right)$ were added to the MSM, the concentrations of the $4 \mathrm{NCB}$ residue were $75.6 \mathrm{mg} / \mathrm{L}$, $70.9 \mathrm{mg} / \mathrm{L}, 75.8 \mathrm{mg} / \mathrm{L}$, and $83.7 \mathrm{mg} / \mathrm{L}$, respectively. These results indicated that the additional reductant could catalyze the 4NCB biodegradation rate of soil microorganisms. However, in soil, the additional reductant had a negligible effect on 4 NCB reduction due to the complex compounds in the soil (Fig. 1B). The 4 NCB biodegradation rate ranged from $47.1-54.3 \%$ with reductant compared with $50.4 \%$ for the control.

However, the utilization of biostimulation with a substrate or a reductant to enhance 4NCB removal from soil warrants further evaluation.

\section{Synergistic Effect of the Reductant and Peptone on 4NCB Reduction.}

With the synergistic effect of the optimal mixture, the 4NCB and nitrobenzene biodegradation rates for target strains from various environments were effectively enhanced [18]. Thus, it was important to evaluate whether the approach could be utilized to effectively enhance 4NCB biodegradation rates using soil microorganisms. When supplementing MSM with peptone and reductants (control, D-glucose, ascorbic acid, mannitol and $\mathrm{Fe}^{2+}$ ), the $4 \mathrm{NCB}$ residue concentrations from an initial concentration of $100 \mathrm{mg} / \mathrm{L} 4 \mathrm{NCB}$ were $83.1 \pm 3.9 \mathrm{mg} / \mathrm{L}, 36.5 \pm 1.2 \mathrm{mg} / \mathrm{L}, 1.1 \pm 0.9 \mathrm{mg} / \mathrm{L}, 11.9 \pm 2.5 \mathrm{mg} / \mathrm{L}$ and $18.4 \pm$ $3.5 \mathrm{mg} / \mathrm{L}$, respectively, after 3 days. In addition, the $O D_{600}$ data were $0.160 \pm 0.017,1.29 \pm 0.105,1.404 \pm$ $0.015,1.48 \pm 0.5244$ and $1.49 \pm 0.102$, respectively. When soil was amended with peptone and reductants (control, peptone, peptone + D-glucose, ascorbic acid + peptone, mannitol + peptone and $\mathrm{Fe}^{2+}+$ peptone), the $4 \mathrm{NCB}$ residue concentrations from an initial concentration of $100 \mathrm{mg} \mathrm{kg}^{-1} 4 \mathrm{NCB}$ were $49.6 \pm$ $2.8 \mathrm{mg} / \mathrm{kg}, 21.7 \pm 3.2 \mathrm{mg} / \mathrm{kg}, 22.5 \pm 4.5 \mathrm{mg} / \mathrm{kg}, 3.3 \pm 1.6 \mathrm{mg} / \mathrm{kg}, 12.7 \pm 2.4 \mathrm{mg} / \mathrm{kg}$ and $10.2 \pm 2.2 \mathrm{mg} / \mathrm{kg}$, respectively. These results show that the optimal mixture (ascorbic acid + peptone) could be effectively utilized to enhance $4 \mathrm{NCB}$ removal in soil with a low initial content of $4 \mathrm{NCB}$. The variations of residual $4 \mathrm{NCB}$ concentrations in soil were examined when the initial 4NCB concentration was $1 \mathrm{~g} / \mathrm{kg} 4 \mathrm{NCB}$ (Fig. 4). After 4-8 days, the level of 4 NCB treatment using the control was negligible. The treatment maintained a level of $72.9 \%(729.2 \pm 71.2 \mathrm{mg} / \mathrm{kg})$ of the initial concentration. As verification of the eased from $1 \mathrm{~g} \mathrm{~kg}^{-1}$ to $43.8 \pm 14.6 \mathrm{mg} \mathrm{kg}^{-1}$ after 6 days 
(Fig. 4), and additional 4NCB was completely degraded after 8 days. Thus, the approach may be a potent technique to treat soil contaminated with $4 \mathrm{NCB}$.

To identify the co-metabolic pathway in soil that contributed to effectively utilizing the approach, GC/MS analysis of $1 \mathrm{~g} / \mathrm{kg}$ 4NCB biodegraded products in soil was performed using the organic extracts of the isolate. The retention time and $\mathrm{m} / \mathrm{z}$ spectra of the identified co-metabolites are shown in Fig. 5. Two major co-metabolites were found: 4-chloroaniline and 4-chloroformanilide. No previous reports have described the 4-chloroformanilide metabolite.

\section{Discussion}

In this study, indigenous microorganisms were a key factor in biostimulation affecting the degradation rate of organic compounds in soil. Due to the interference caused by complex compounds in soil, it is reasonable that these compounds would affect the removal rate of 4 NCB as well as the biomass of indigenous microorganisms. Reducing the interference from these complex compounds in soil would help optimize 4NCB removal, but reducing the interference in the soil system to a level that could eliminate the effect of soil compounds is almost impossible. The soil bacteria were counted using a miniaturized most likely number (MPN) method $(21,22)$ and the soil microbial communities were determined by nucleotide sequence analyses and $16 \mathrm{~S}$ rRNA-based denatured gradient gel electrophoresis $(23,24)$. However, the two methods could not be utilized to characterize the effect of the additional compound on the microbial biomass and 4 NCB biodegradation. As a result, we evaluated several additional compounds to determine their effects on the biomass of the indigenous soil microorganisms and the 4 NCB biodegradation rate in the MSM. In our experiment, the distribution of microbial communities of the same population was associated with the soil and MSM because the microbial communities were obtained from the same soil in two systems. The MSM results could be less influenced by soil compounds and directly reflect the effect of the additional compound on organic contaminant removal by the soil microbial communities. In the study, two strategies of biostimulation were utilized to enhance 4 NCB removal. Firstly, we utilized co-metabolism to enhance the 4NCB removal rate. Generally, a key factor of successful co-metabolism is needed to enhance the biomass of microorganisms. In the experiment, an additional carbon source could not be used to enhance the 4NCB contaminant removal in soil because the organic carbon as a sole source was not sufficient to support the growth of indigenous microbes in the soil (Fig. 3). Conversely, a notable increase in both the biomass and biodegradation rate was observed because of supplementation with organic nitrogen. The reason appears to be that nitrogen from $4 \mathrm{NCB}$ was utilized by the strains to generate energy to drive metabolic reactions rather than to produce new biomass, while carbon from 4 NCB was utilized by the strains to produce new biomass (18). A series of studies indicated that the addition of inorganic or organic nitrogen-rich nutrients (biostimulation) is an effective approach to enhancing the bioremediation process (25). However, in our experiment, the additional inorganic nitrogen or organic nitrogen produced opposite results regarding their effect on the biodegradation of nitroaromatic compounds. The reason may be that an inorganic nitrogen source has limited bioavailability to soil microorganisms. The findings suggested that only an 
organic nitrogen source could enhance the $4 \mathrm{NCB}$ biodegradation rate by increasing the biomass of indigenous microorganisms in soil.

The other strategy is to utilize additional reductant to enhance 4 NCB degradation. Interesting findings on this strategy were as follows: 1 ) In MSM, the reductant (electron donors) as the sole additional agent could not support microbial growth but could enhance the 4 NCB removal rate from soil by the microbial communities (Fig. 2A). These results are consistent with past studies reporting that the additional reductant could catalyze the nitroaromatic compounds biodegradation rate $(18,19,26,27)$. 2$)$ In soil, no positive effect on the 4 NCB removal rate was observed when the reductant was added. This finding raises an interesting question as to why the addition of the same reductant in two systems has different effects. The reasons may be as follows: 1) The additional reductant could enhance 4NCB bioreduction while the indigenous microorganisms and the additional reductant encounter each other. In MSM, the additional reductant and the indigenous microorganisms continue to move, creating ongoing contact between the reductant and the microorganisms, which causes the 4NCB bioreduction rate to be enhanced; however, in soil, both the limited biomass of indigenous microorganisms and the additional agent could be adsorbed in a limited space (28), minimizing the contact between the microorganisms and additional reductant. 2) The other reason may be a chemical reaction of the additional reductant with complex soil compounds, the interaction between the additional reductant and complex soil compounds, etc.

An additional reductant (alkaline ascorbic acid) has been suggesting to exhibit the potential to reductively degrade similar compounds such as nitrobenzene in soil (29), but it is unclear why the additional ascorbic acid would have opposite results regarding its effect on similar compounds (nitrobenzene, $4 \mathrm{NCB}$ ). In the present study, $80 \%$ of nitrobenzene was degraded in a soil slurry with a high water to soil ratio $(>85 \%, w / w)$; the soil slurry under these conditions was in an aqueous phase. Moreover, maintaining a high alkaline $\mathrm{pH}$ is essential for the ascorbic acid effect on $4 \mathrm{NCB}$ removal. Therefore, with a normal water to soil ratio $(<20 \%)$, the additional alkaline ascorbic acid has no obvious impact on the $4 \mathrm{NCB}$ removal in neutral soil in the experiment (29). These results further demonstrate that effectively removing $4 \mathrm{NCB}$ in untreated soil solely using an additional reductant is impossible.

Finally, the use of two cooperative strategies can effectively remove 4NCB. The results of our experiments indicated a similar tendency consistent with previous MSM studies suggesting that a treatment using a combination of a reductant and a substrate is more effective than a treatment using either component individually $(18,19)$. Thus, the liquid system could be utilized to reduce the interference of the soil compounds and to evaluate the effect of the additional compound on the biomass of indigenous microorganisms and the 4 NCB degradation rate.

However, testing the synergistic effect is the key step in the experimental process. Three types of mixtures (reductant $\mathrm{Vc}+$ peptone, mannitol + peptone, and $\mathrm{Fe}^{2+}+$ peptone) appeared to have a positive synergistic effect on 4 NCB removal in soil, but only one mixture (D-glucose + peptone) had no positive synergistic fffant an $1 \mathrm{~N} \cap \mathrm{R}$ ramanul In coil an nvictinn prganic reductant is present (30), which calls into question Loading [MathJax]/jax/output/CommonHTML/jax.js

Page 10/20 
the need for an additional reductant. However, the additional optimal reductant was useful in effectively removing $4 \mathrm{NCB}$ from soil for the following reasons: 1) Using some additional reductant does not impact the synergistic effect on 4 NCB removal in soil. For example, no noticeable difference was observed in the $4 \mathrm{NCB}$ removal rate in soil for the experimental data using additional glucose and peptone compared to the data using only additional peptone. Thus, organic reductant and peptone in soil may not always produce a synergistic effect on 4 NCB removal from soil. 2) The process of adding peptone to soil to enhance the $4 \mathrm{NCB}$ removal rate still needs improvement. Luan et al. demonstrated that the enhancement of nitrobenzene bioreduction is dependent on the availability of excess electron donors (31). Therefore, due to the excess number of electron donors using the additional reductant, the optimal combination of reductant and peptone will have an improved synergistic effect on the 4NCB removal from soil. 3) Based on our previous studies, the effects of the same mixture (reductant and substrate) on the ability of different strains to remove nitrobenzene or 4 NCB may be different $(18,19)$. The microbial communities under different soil conditions were different regarding the distribution of cells, causing the same mixture to have a different synergistic effect. Thus, identifying the optimal mixture to effectively enhance the reduction of $4 \mathrm{NCB}$ from soil was important. A series of studies on biostimulation through iron reduction have been published $(9,32)$. In our studies, two mixtures (Vc and peptone and mannitol and peptone) produced better results for the synergistic effect of $4 \mathrm{NCB}$ removal in soil than $\mathrm{Fe}^{2+}$ with peptone. These results are consistent with our previous studies and demonstrate that mixtures using an organic reductant allow more choices and are less toxic $(18,19)$. With the optimal mixture (Vc and peptone), $1 \mathrm{~g} / \mathrm{kg} 4 \mathrm{NCB}$ in soil was almost completely removed after 8 days. Niu et al. performed bioaugmentation of a soil contaminated with 4-chloronitrobenzene using a Pseudomonas putida ZWL73 strain, which produced similar effects on the 4 NCB removal rate (33), but the success of this approach was limited because the inoculated microbes could not survive in the target soils. However, soil with indigenous microorganisms with the ability to biodegrade 4NCB may exist in various environments (18); thus, biostimulation using their approach proved to be an effective strategy for treating soil contaminated with $4 \mathrm{NCB}$ as well as soil contaminated with other nitroaromatic compounds.

A series of studies on $4 \mathrm{NCB}$ metabolic pathways under aerobic conditions have reported the following findings: 1) 4 NCB can be transformed into 4-chloroaniline, N-acetyl-4-chloroaniline, and 4chloronitrosobenzene without any further degradation using the Pseudomonas sp. CBS3 strain (34). 2) A reductive pathway was identified in which yeast (Rhodosporidium sp.) transforms 4NCB to produce 4chloroacetanilide and 4-chloro-2-hydroxyacetanilide (11). 3) The Sphingomonas sp. strain NCB3 can transform 4NCB into 4-chloroaniline (7). However, no information on the 4NCB co-metabolic pathway has been reported. GC/MS analysis of co-metabolites were utilized to identify two compounds (4chloroaniline and 4-chloroformanilide). 4-Chloroaniline has been reported to function as a normal metabolite under aerobic conditions. For example, two co-metabolic pathways exist for 4-chloroaniline: 1) 4 NCB can be transformed into 4-chloroaniline by the microbial strains. The first pathway is the transformation of 4-chloroaniline into 2-amino-5-chlorophenol, after which this species can be further transformed into 5-chloropicolinic acid (33). 2) Certain strains directly transform 4-chloroaniline via ring chavanan nathisave (25) In thn nunnrimant 2-amino-5-chlorophenol was not detected by GC/MS in the Loading [MathJax]/jax/output/CommonHTML/jax.js

Page $11 / 20$ 
soil; therefore, 4NCB may have been directly transformed into 4-chloroaniline via ring cleavage in this experiment. Here, we utilized the approach of transforming 4NCB into 4-chloroformanilide in soil to demonstrate the presence of a novel co-metabolic pathway for 4 NCB due to the function of a novel metabolite. In addition, the metabolites indicated that the initial phase of 4 NCB biodegradation is based on reductive pathways in soil; therefore, the additional reductant may be a catalyst for $4 \mathrm{NCB}$ biodegradation.

\section{Conclusion}

In the previously studies, we established a novel approach that could efficiently enhance the rate of the strains' nitroaromtic compounds biodegradation by the synergistic effect of combining a organic reductant with a substrate. In the manuscript, utilizing the approach, $1 \mathrm{~g}$ 4-chloronitrobenzene $\mathrm{kg}^{-1}$ soil could be effectively removed from soil after 8 days. Furthermore, in soil, our results disclosed that were two 4-chloronitrobenzene co-metabolic pathways by utilizing the approach, and one of the ways is a novel metabolic pathway that 4-chloronitrobenzene was transformed to 4-chlorofromanilide. In addition, the approach may provide a potential method for treating soil contaminated with 4-chloronitrobenzene as well as other nitroaromatic compounds.

\section{Declarations}

\section{Availability of data and materials}

The data sets used and analysed during the current study are available from the corresponding author upon reasonable request.

\section{Ethics approval and consent to participate}

Not applicable.

\section{Consent for publication}

Not applicable.

\section{Competing interests}

The authors declare that they have no competing interests.

\section{Funding}

This work was supported by the National Key Research and Development Program of China (No: 2017YFD0200301). 


\section{Authors' contributions}

Tian Li, Ping Zhang, Kun Qian1 were involved in the experiments, manuscript writing, and data analysis.

Tian $\mathrm{C} \otimes$ Zhang contributed to the study design and manuscript correction. All authors read and approved the final manuscript.

\section{Acknowledgements}

Not applicable.

\section{Author details}

${ }^{1}$ Southwest University, Chongqing 400715, P. R. China. ${ }^{2}$ Civil Engineering Department, University of Nebraska-Lincoln, Omaha, NE, USA.

\section{References}

1. Xia S, Li H, Zhang Z, Zhang Y, Yang X, Jia R, Xie K, Xu X (2011) Bioreduction of parachloronitrobenzene in drinking water using a continuous stirred hydrogen-based hollow fiber membrane biofilm reactor. J Hazard Mater 192:593-598

2. Zhu L, Gao K, Qi J, Jin J, Xu X (2014) Enhanced reductive transformation of p-chloronitrobenzene in a novel bioelectrode-UASB coupled system. Bioresour Technol 167:303-309

3. Azaizeh H, Castro PML, Kidd P (2011) Biodegradation of Organic Xenobiotic Pollutants in the Rhizosphere. Springer Netherlands 191-215 p

4. Lladó S, Solanas AM, De LJ, Borràs M, Viñas M (2012) A diversified approach to evaluate biostimulation and bioaugmentation strategies for heavy-oil-contaminated soil. Sci Total Environ 435-436:262-269

5. Martínhernández M, Suárezojeda ME, Carrera J (2012) Bioaugmentation for treating transient or continuous $\mathrm{p}$-nitrophenol shock loads in an aerobic sequencing batch reactor. Bioresour Technol 123:150-156

6. Horemans B, Breugelmans P, Saeys W, Springael D (2017) A soil-bacterium compatibility model as a decision-making tool for soil bioremediation. Environ Sc Technol 51:1605-1615

7. Zhang L, Wang X, Jiao Y, Chen X, Zhou L, Guo K, Ge F, Wu J (2013) Biodegradation of 4chloronitrobenzene by biochemical cooperation between Sphingomonas sp. strain CNB3 and Burkholderia sp. strain CAN6 isolated from activated sludge. Chemosphere 91:1243-1249

8. Zhen D, Liu H, Wang SJ, Zhang JJ, Zhao F, Zhou NY (2006) Plasmid-mediated degradation of 4chloronitrobenzene by newly isolated Pseudomonas putida strain ZWL73. Appl Environ Microb 72:797-803 
9. Katsivela E, Wray V, Pieper DH (1999) Wittich RM Initial reactions in the biodegradation of 1-chloro-4nitrobenzene by a newly isolated bacterium, strain LW1. Appl Environ Microb 65:1405-1412

10. Bisgaard MK, Søren (2007) Plant-microbe association for rhizoremediation of chloronitroaromatic pollutants with Comamonas sp. strain CNB-1. Environ Microbiol 9:465-473

11. Niu GL, Zhang JJ, Zhao S, Liu H, Boon N, Zhou NY (2009) Bioaugmentation of a 4chloronitrobenzene contaminated soil with Pseudomonas putida ZWL73. Environ Pollu 157:763771

12. Crisafi F, Genovese M, Smedile F, Russo D, Catalfamo M, Yakimov M, Giuliano L, Denaro R (2016) Bioremediation technologies for polluted seawater sampled after an oil-spill in Taranto Gulf (Italy): A comparison of biostimulation, bioaugmentation and use of a washing agent in microcosm studies. Mar Pollut Bull 106:119-126

13. Kauppi S (2011) Enhancing bioremediation of diesel-fuel-contaminated soil in a boreal climate: Comparison of biostimulation and bioaugmentation. Int Biodeter Biodegr 65:359-368

14. Nikolopoulou M, Pasadakis N, Kalogerakis N (2013) Evaluation of autochthonous bioaugmentation and biostimulation during microcosm-simulated oil spills. Mar Pollut Bull 72:165-173

15. Dias RL, Ruberto L, Hernández E, Vázquez SC, Balbo AL, Panno MTD, Cormack WPM (2012) Bioremediation of an aged diesel oil-contaminated Antarctic soil: Evaluation of the " on site" biostimulation strategy using different nutrient sources. Int Biodeter Biodegr 75:96-103

16. Pimmata P, Reungsang A, Plangklang P (2013) Comparative bioremediation of carbofuran contaminated soil by natural attenuation, bioaugmentation and biostimulation. Int Biodeter Biodegr 85:196-204

17. Baek K, Mckeever R, Rieber K, Sheppard D, Park C, Ergas SJ, Nüsslein K (2012) Molecular approach to evaluate biostimulation of 1,2-dibromoethane in contaminated groundwater. Bioresour Technol 123:207-213

18. Li T, Zhang TC, He L (2017) A Novel Method for Enhancing Strains' Biodegradation of 4Chloronitrobenzene. J Biotechnol 264:8-16

19. Li T, Zhou Z, He L (2017) A novel approach for enhancing bacterial strains' Nitrobenzene degradation rate. Int Biodeter Biodegr 123:63-69

20. Wolińska A, Kuźniar A, Szafranek-Nakonieczna A, Jastrzębska N, Roguska E, Stępniewska Z (2016) Biological Activity of Autochthonic Bacterial Community in Oil-Contaminated Soil. Water Air Soil Poll 227:130 (1-12)

21. Lu L, Huggins T, Jin S, Zuo Y, Ren ZJ (2014) Microbial metabolism and community structure in response to bioelectrochemically enhanced remediation of petroleum hydrocarbon-contaminated soil. Environ Sc Technol 48:4021-4029

22. Lee PKH, Warnecke F, Brodie EL, Macbeth TW, Conrad ME, Andersen GL, Alvarezcohen L (2012) Phylogenetic Microarray Analysis of a Microbial Community Performing Reductive Dechlorination at a TCE-contaminated Site. Environ Sc Technol 46:1044-1054 
23. Gat D, Ronen Z, Tsesarsky M (2016) Soil Bacteria Population Dynamics Following Stimulation for Ureolytic Microbial-Induced CaCO3 Precipitation. Environ Sc Technol 50:616-624

24. Gong XB (2012) Remediation of weathered petroleum oil-contaminated soil using a combination of biostimulation and modified Fenton oxidation. Int Biodeter Biodegr 70:89-95

25. Shahi A, Aydin S, Ince B, Ince O (2016) Reconstruction of Bacterial Community Structure and Variation for Enhanced Petroleum Hydrocarbons Degradation Through Biostimulation of Oil Contaminated Soil. Chem Eng J 306:60-66

26. Sun HW, Xu XY, Gao GD, Zhang ZZ, Yin PJ (2010) A novel integrated active capping technique for the remediation of nitrobenzene-contaminated sediment. J Hazard Mater 182:184-190

27. Wen YJ, Yang YS, Ren HJ, Du XQ, Yang XY, Zhang LY, Wang XS (2015) Chemical-biological hybrid reactive zones and their impact on biodiversity of remediation of the nitrobenzene and aniline contaminated groundwater. Chem Eng J 280:233-240

28. Adam G, Gamoh K, Morris DG, Duncan H (2002) Effect of alcohol addition on the movement of petroleum hydrocarbon fuels in soil. Sci Total Environ 286:15-25

29. Liang C, Lin YT, Shiu JW (2016) Reduction of nitrobenzene with alkaline ascorbic acid: Kinetics and pathways. J Hazard Mater 302:137-143

30. Chen M, Shih K, Hu M, Li F, Liu C, Wu W, Tong H (2012) Biostimulation of indigenous microbial communities for anaerobic transformation of pentachlorophenol in paddy soils of southern China. $\mathrm{J}$ AGR FOOD CHEM 60:2967-2975

31. Luan F, Burgos WD, Li X, Qi Z (2010) Bioreduction of Nitrobenzene, Natural Organic Matter, and Hematite by Shewanella putrefaciens CN32. Environ Sc Technol 44:184-190

32. Komlos J, Kukkadapu RK, Zachara JM, Jaffé PR (2007) Biostimulation of iron reduction and subsequent oxidation of sediment containing Fe-silicates and Fe-oxides: Effect of redox cycling on Fe(III) bioreduction. Water Res 41:2996-3004

33. Schackmann A, Müller R (1991) Reduction of nitroaromatic compounds by different Pseudomonas species under aerobic conditions. APPL MICROBIOL BIOT 34:809-813

34. Lovley D, Callister SJ, Wilkins MJ, Nicora CD, Williams KH, Banfield JF, Verberkmoes NC, Hettich RL, N'Guessan L, Mouser PJ (2010) Analysis of Biostimulation Microbial Communities from Two Field Experiments Reveals Temporal and Spatial Differences in Proteome. Environ Sc Technol 44:88978903

35. Corbett MD, Corbett BR (1981) Metabolism of 4-Chloronitrobenzene by the Yeast Rhodosporidium sp. APPL MICROBIOL BIOT 41:942-949

\section{Figures}



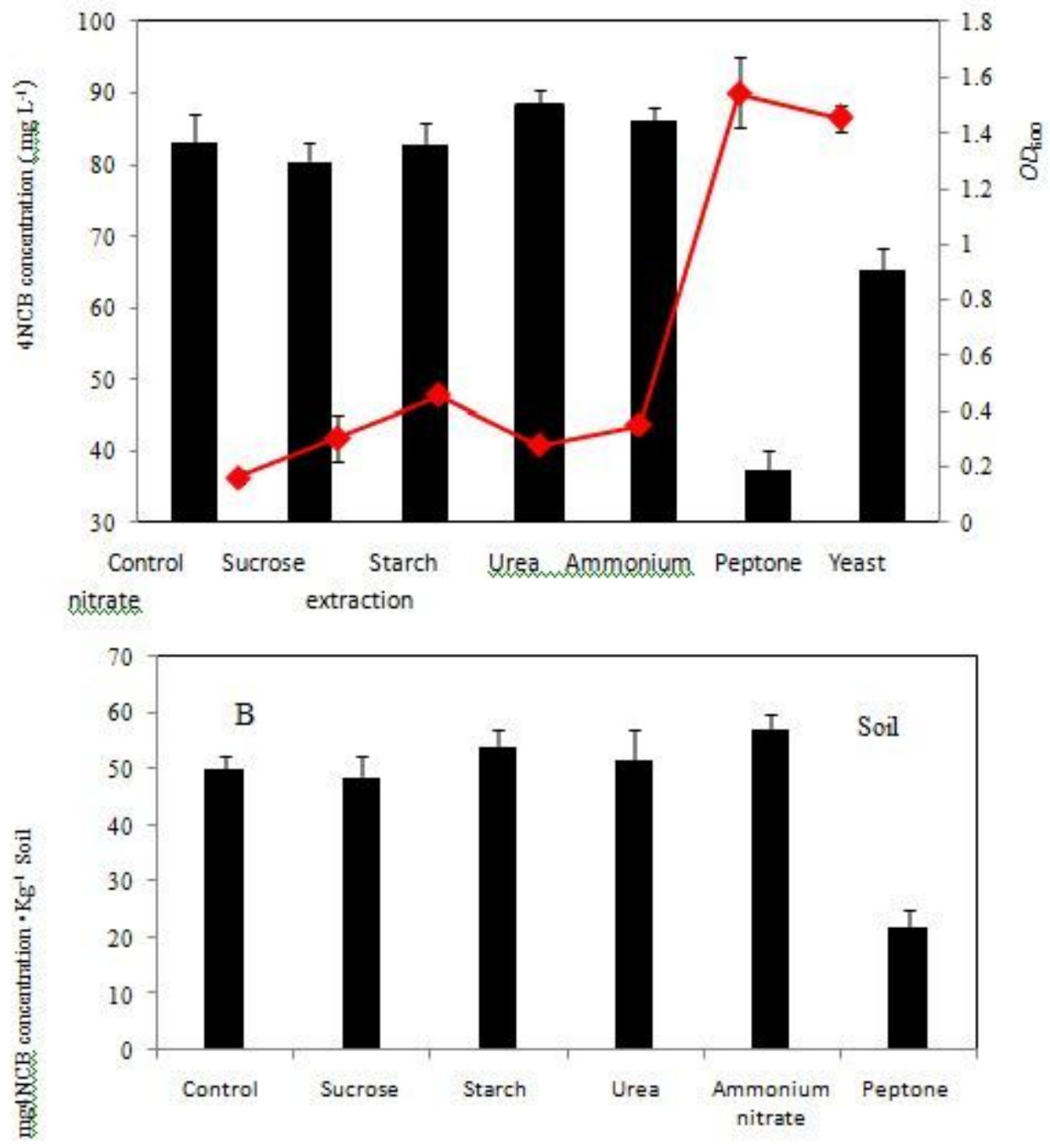

Figure 1

Effects of reductants(Control, D-glucose, Mannitol, VC, and Fe2+)on 4NCB degradation and microbial biomass in MSM after 3days. (A) The amount of residue from 100mg/L4NCB and the OD600 of the indigenous microorganisms.(B) The amount of residue from $100 \mathrm{mg} 4 \mathrm{NCB} / 1 \mathrm{~kg}$ soil. 

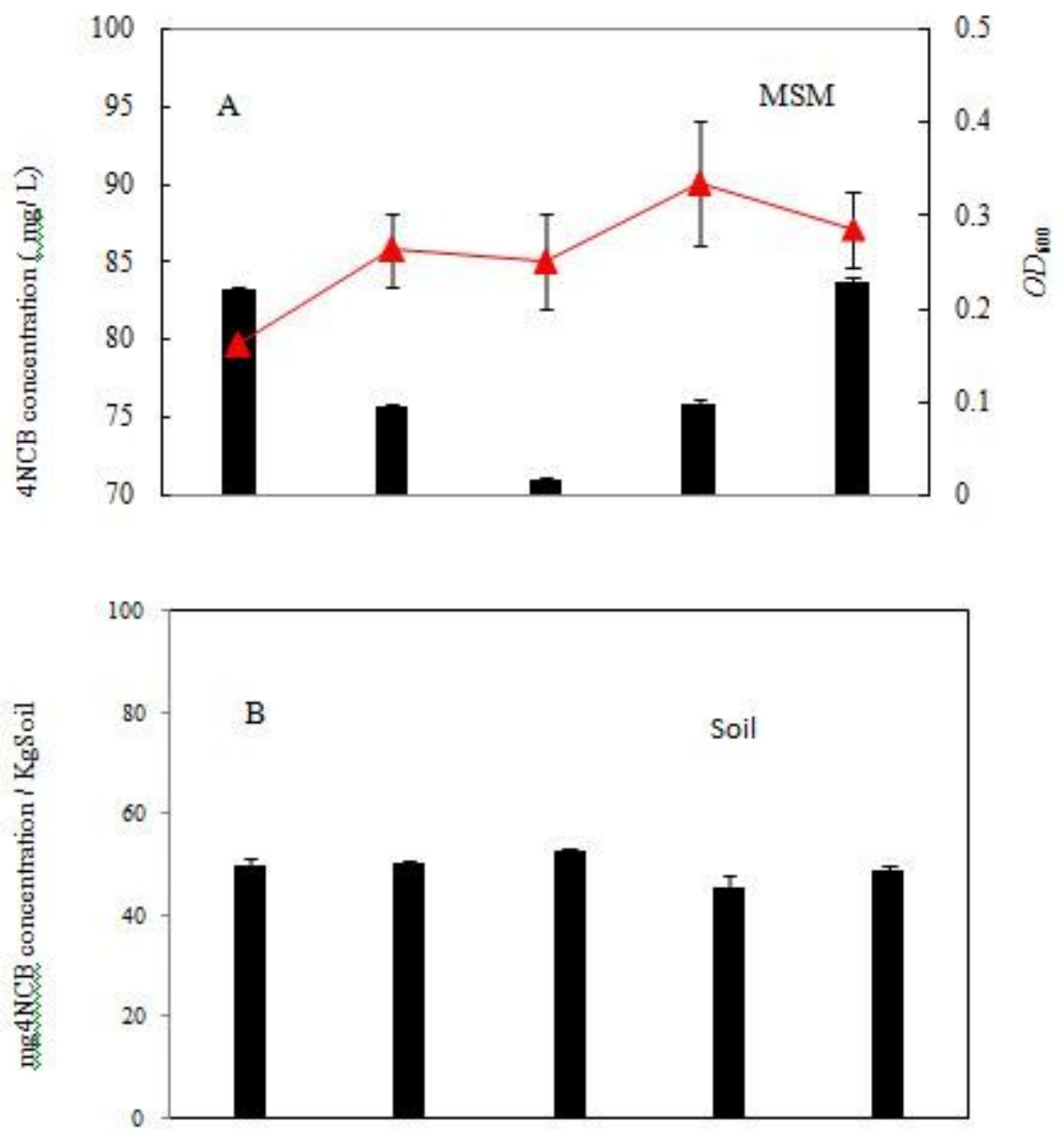

Figure 2

Effect of the substrate(Control, Sucrose, Starch, Urea, Ammonium nitrate, and Peptone)on 4NCB degradation in the two systems after 3days.(A) The concentrations of 4 NCB residue from an initial level of $100 \mathrm{mg} / \mathrm{L}$ and the OD600 of the indigenous microorganisms.(B) The residuecontent from $100 \mathrm{mg} 4 \mathrm{NCB} / 1 \mathrm{~kg}$ soil. 

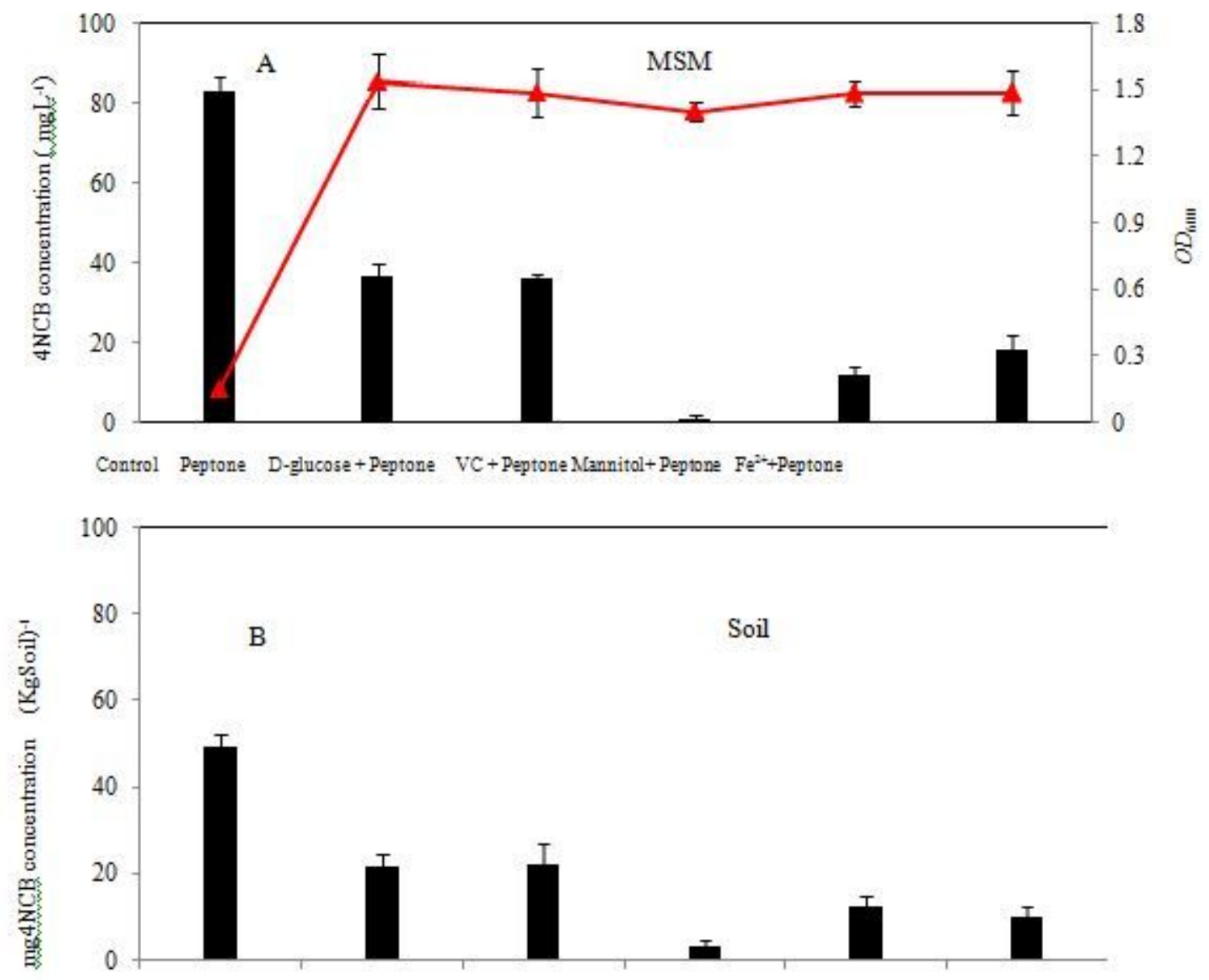

Control Peptone D-glucose+Peptone VC+Peptone Mannitol + Peptone Fe't+Peptone

\section{Figure 3}

Synergistic effect of areductantand peptone(Control, Peptone, D-glucose + Peptone, VC + Peptone, mannitol + Peptone and Fe + Peptone) on 4NCB degradation after 3days.(A) The concentrations of 4NCB residue from an initial level of 100mg /Land the OD600 of the indigenous microorganisms.(B) The residuecontent from $100 \mathrm{mg} 4 \mathrm{NCB} / 1 \mathrm{~kg}$ soil. 


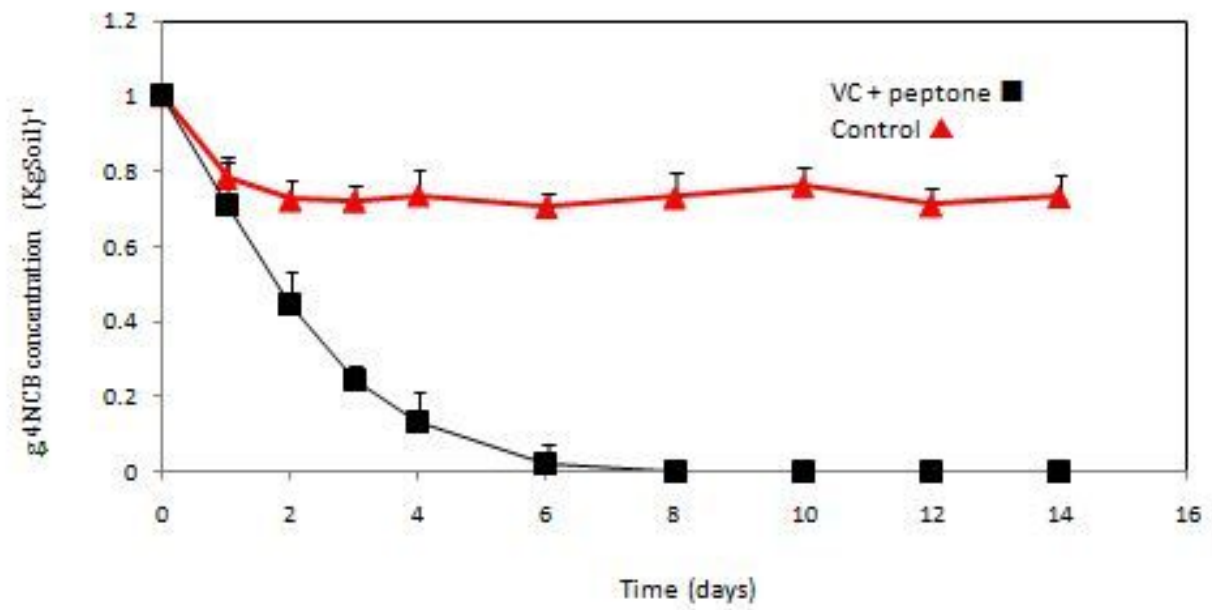

Figure 4

Utilizing the developed approach to treatlaboratory-scale 4NCB-contaminatedsoil.
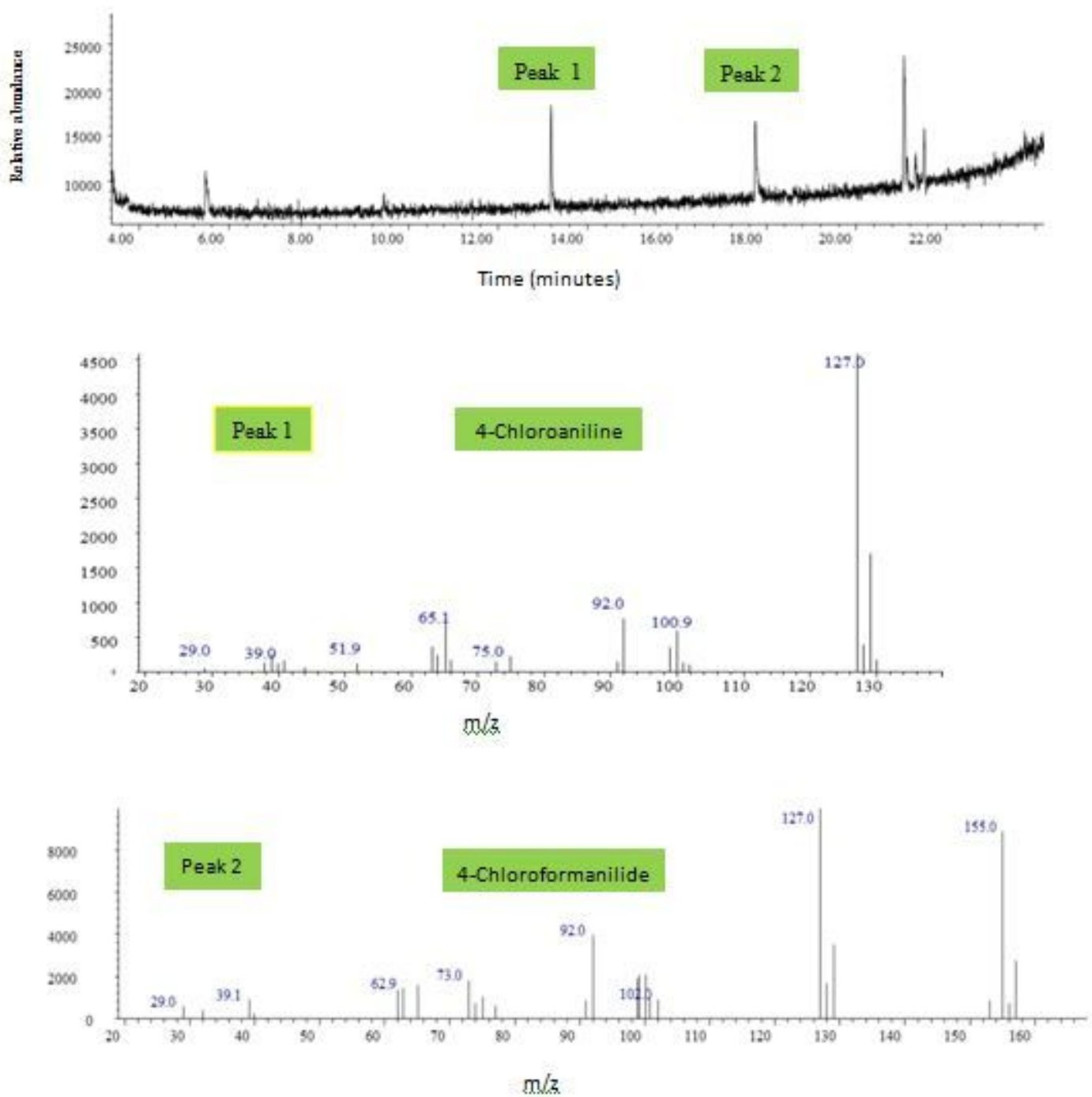
GC/MS analysis of the metabolites of 4NCB.

\section{Supplementary Files}

This is a list of supplementary files associated with this preprint. Click to download.

- AMECertificate52786.pdf 